\title{
Jaw reconstruction with vascularized fibular flap: The 11-year experience among 104 patients
}

\author{
Shengjie Shao, Weihong Wang ${ }^{*}$, Biao Xu, Yu Liu and Zhe Zhang
}

\begin{abstract}
Background: A vascularized fibular osteomyocutaneous flap with severe vascular crisis often results in serious consequences. This study aims to examine the clinical effect of non-vascularized fibular graft on patients with severe vascular crisis after reconstruction of the defect jaw with vascularized fibular osteomyocutaneous flap.

Materials and methods: From December 2007 to December 2018, a total of 104 patients with jaw neoplasms that underwent reconstruction with free vascularized fibular flap were retrospectively analyzed; seven of these cases had postoperative vascular crisis during mandibular reconstruction.

Results: Of the seven cases with postoperative vascular crisis, the vascularized fibular flaps in three patients survived completely, thanks to early detection; two cases were completely necrotic and removed in the end, and the remaining two cases had severe vascular crisis after the removal of the soft tissue attached to the fibular flap. The non-vascular fibular grafts were retained regardless of the severe absorption after follow-ups for 25 and 69 months, respectively.

Conclusions: If vascular crisis occurs following jaw reconstruction with a vascularized fibular osteomyocutaneous flap, early re-surgical exploration effectively improves the salvage rate. In addition, when a severe vascular crisis occurs, the vascularized fibular flap can be changed to a non-vascular fibular graft to reconstruct the mandibular defect, thus avoiding the serious consequences resulting from the complete failure of fibular graft.
\end{abstract}

Keywords: Vascularized fibular osteomyocutaneous flap, Non-vascularized fibular graft, Severe vascular crisis, Jaw defect

\section{Introduction}

Vascularized fibular osteomyocutaneous flap has been currently advocated in jaw reconstruction for large defects, which contributes to the restoration of the facial appearance and chewing function of the patient [1-3]. Notably, vascular anastomosis is required in a free tissue flap; therefore, it is of great importance to detect vascular crisis in the anastomotic blood vessels at the early

\footnotetext{
* Correspondence: wwh2002191@163.com

Department of Oral and Maxillofacial Surgery, Affiliated Stomatology Hospital of Kunming, Medical University, No. 1088 Mid Hai Yuan Road, Gaoxin District, Kunming 650106, Yunnan, China
}

stage, and to carry out surgical exploration and treatment immediately for achieving successful operation. The delayed discovery of vascular crisis or the presence of the more serious vascular crisis may result in complete necrosis of the free transplanted tissue flap, thereby inducing severe consequences [4-9]. In this study, to avoid serious consequences induced by the vascularized fibular osteomyocutaneous flap with severe vascular crisis, the vascularized fibular osteomyocutaneous flaps in two cases with severe vascular crisis were immediately managed using the non-vascularized fibular

(c) The Author(s). 2020 Open Access This article is licensed under a Creative Commons Attribution 4.0 International License, which permits use, sharing, adaptation, distribution and reproduction in any medium or format, as long as you give appropriate credit to the original author(s) and the source, provide a link to the Creative Commons licence, and indicate if changes were made. The images or other third party material in this article are included in the article's Creative Commons licence, unless indicated otherwise in a credit line to the material. If material is not included in the article's Creative Commons licence and your intended use is not permitted by statutory regulation or exceeds the permitted use, you will need to obtain permission directly from the copyright holder. To view a copy of this licence, visit http://creativecommons.org/licenses/by/4.0/ The Creative Commons Public Domain Dedication waiver (http://creativecommons.org/publicdomain/zero/1.0/) applies to the data made available in this article, unless otherwise stated in a credit line to the data. 
grafts. As a result, this remedial treatment contributed to achieving certain clinical effects.

\section{Patients and methods}

From December 2007 to December 2018, 104 patients, including 57 males and 47 females with jaw neoplasms, were retrospectively analyzed at the Department of Oral and Maxillofacial Surgery of the Affiliated Stomatological Hospital of Kunming Medical University. This study protocol was approval by the Human Body Science Committee of Kunming Medical University. All patients provided a written form of consent for the use of their medical information. The vascularized fibular bone flap was immediately reconstructed upon the removal of the jaw neoplasm, and it was then fixed using the YZB2.0 craniotomy system titanium plate and screws (Shenzhen Putianyang Medical Instrument Co., Ltd). The age of patients ranged from 15 to 66 years, with an average of 38.6 years. Of all the enrolled 104 patients, 90 had ameloblastomas, 2 had myxomas, 1 had ossifying fibroma, 1 had odontoma, 7 had squamous cell carcinomas, and 3 had osteosarcomas. Among them, 94 cases had neoplasms in the mandible, while the remaining 10 had tumors in the maxilla. The clinical data of these 7 patients are presented in Table 1.

More details of jaw reconstruction are described in our previous reports $[10,11]$. Six out of these 7 patients with vascular crisis received immediate surgical exploration under general anesthesia through nasal endotracheal intubation. Afterwards, the wound was washed with a large amount of warm saline, and later the anastomotic artery, vein, fibular bone flap, and fibular perforator vessel were exposed. Two out of these 7 patients with venous crisis received anastomotic incision and re-anastomosis after repeated washing with heparin sodium saline. Moreover, another two patients received partial compression in the perforating vascular pedicle of the skin paddle, and the perforator flaps were removed (Fig. 1). For the remaining two cases, no blood flow was observed after the vein at the anastomotic site was cut. However, the vascularized fibular osteomyocutaneous flap was extensively congested, which induced a severe arterial and venous crisis. Therefore, the fibular bone flaps were removed; meanwhile, all soft tissues attached to the fibular bone including the arteries, veins, flexor hallucis longus, and skin paddle were also completely removed. Subsequently, the vascularized fibular musculocutaneous flap was treated as the nonvascularized fibular graft, which was reattached to the mandibular stump (Fig. 2). Panoramic radiographs or $\mathrm{CBCT}$ examinations were performed on these cases during the follow-up period.

\section{Results}

In this study, 7 patients, including 5 males and 2 females with the age of 22-51 years (average, 33.7 years) developed postoperative vascular crisis, which was later confirmed as the mandibular ameloblastoma. In 3 patients, the vascularized fibular bone flaps healed favorably after surgical exploration, thanks to the early detection. Another 2 patients developed complete necrosis in the fibular bone flap; among them, one underwent surgical exploration, while the other one did not, and the fibular grafts were finally removed in the latter. The remaining two patients with non-vascular fibular bone flaps were followed up for 25 and 69 months, respectively. The titanium plate was removed in one of the patients 1 year later, while the other one suffered from postoperative local chronic infection for 2 years (Figs. 3 and 4). In this patient, the chronic infection was not controlled until the titanium plate was removed 6 years postoperatively due to severe fibular graft absorption (Fig. 4).

\section{Discussion}

Costal bone and iliac bone may serve as the common donors of non-vascularized bone grafts for the reconstruction of mandibular defects when there is little or no soft tissue loss [2]. By contrast, the vascularized fibular flap is currently adopted for reconstructing large jaw defects, so as to restore the facial contour and chewing function of the patient, and this approach attains a high success rate, with the overall survival rate of up to 9699\% [12, 13]. Nonetheless, some cases still develop postoperative vascular crisis. Under such circumstances,

Table 1 Clinical features of 7 patients with vascular crisis

\begin{tabular}{|c|c|c|c|c|c|c|c|c|c|}
\hline Number & Date & Age(years) & Gender & Diagnosis & Location & Perforator flap & Exploration & Reason & Result \\
\hline 1 & 2010 & 51 & Male & Ameloblastoma & Mandible & No & No & Vascular crisis & Complete necrosis \\
\hline 2 & 2011 & 23 & Male & Ameloblastoma & Mandible & No & Yes & Venous crisis & Complete necrosis \\
\hline 3 & 2013 & 41 & Male & Ameloblastoma & Mandible & Yes & Yes & Severe vascular crisis & Nonvascularized fibular \\
\hline 4 & 2015 & 29 & Male & Ameloblastoma & Mandible & Yes & Yes & Venous crisis & Survived \\
\hline 5 & 2016 & 42 & Female & Ameloblastoma & Mandible & Yes & Yes & Severe vascular crisis & Nonvascularized fibular \\
\hline 6 & 2017 & 28 & Male & Ameloblastoma & Mandible & Yes & Yes & Perforator flap crisis & Survived \\
\hline 7 & 2017 & 22 & Female & Ameloblastoma & Mandible & Yes & Yes & Perforator flap crisis & Survived \\
\hline
\end{tabular}



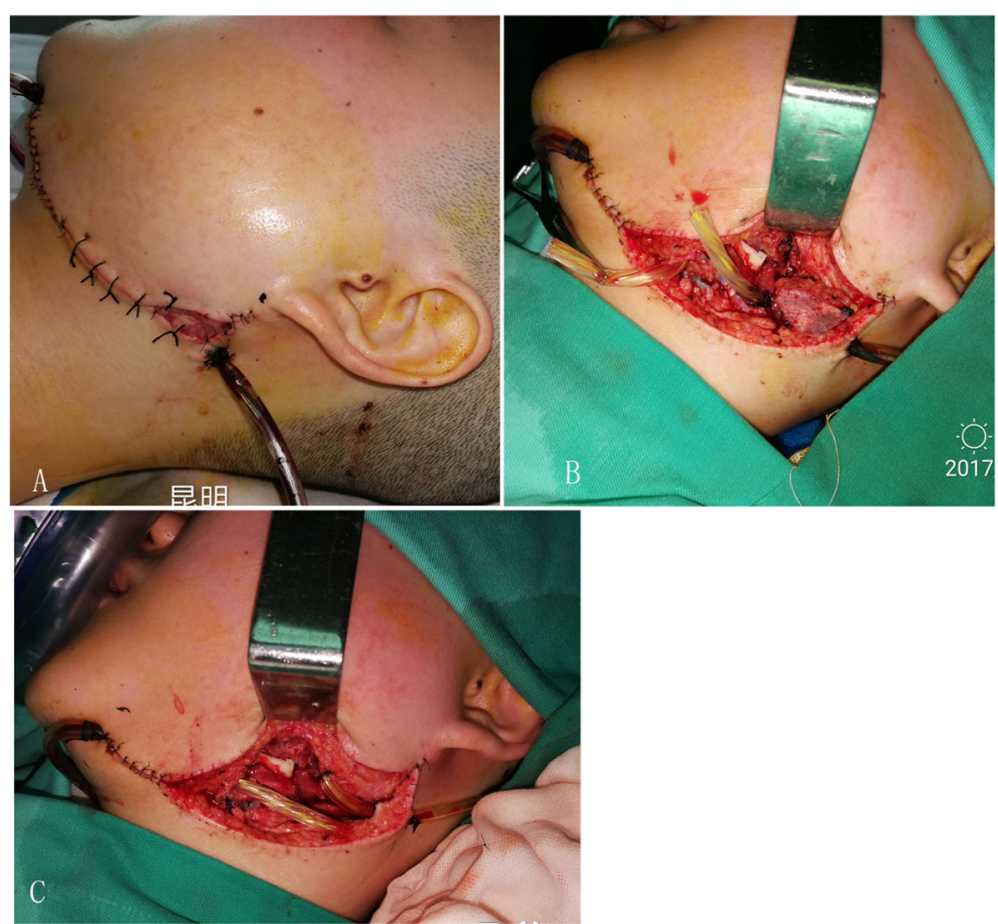

Fig. 1 The pedicle of skin paddle was only partially compressed $(\mathbf{a}, \mathbf{b})$, and the perforator flaps were removed (c)

early surgical exploration is of great significance to attain a successful operation. Notably, the delayed discovery or the presence of a more severe vascular crisis may lead to complete necrosis of the vascularized fibular flap. In this case, the transplanted fibular flap should be removed, and the mandibular defect should be treated by either immediate reconstruction with a vascularized bone flap, or bridging with a reconstruction plate prior to the subsequent mandibular defect reconstruction. However, this method is unfavorable to restore the facial contour and chewing function of patients. Besides, further reconstruction may not be feasible or desirable in some patients [12]. Consequently, it is a suitable temporary remedy to immediately change the vascularized fibular
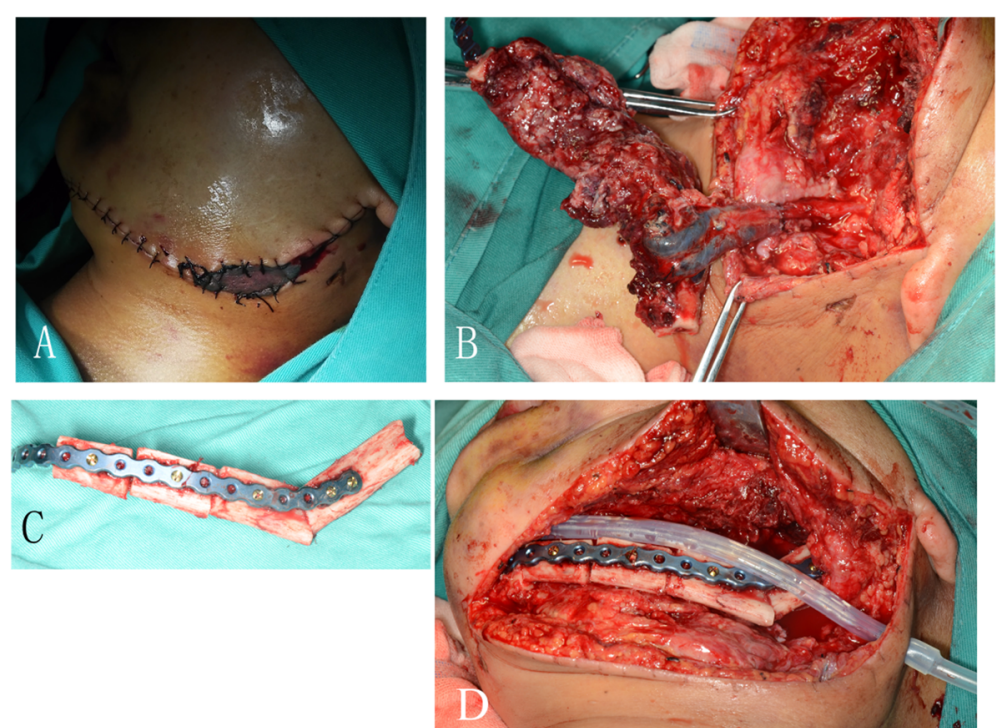

Fig. 2 The vascularized fibular osteomyocutaneous flap was extensively congested, which induced a severe arterial and venous crisis (a, b). All soft tissues attached to the fibular bone including arteries, veins, flexor hallucis longus, and the skin flap were completely removed (c). The nonvascularized fibular bone flap and was reattached to the mandibular stump (d) 

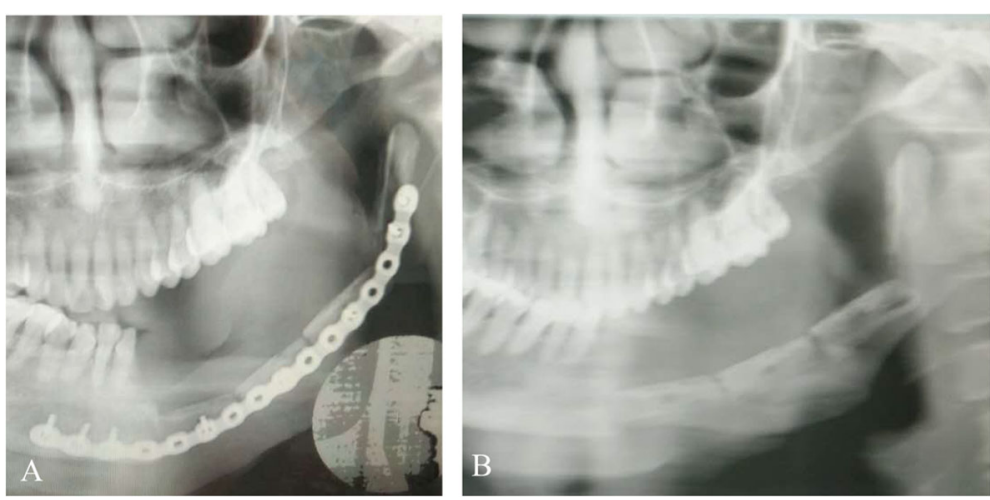

Fig. 3 Panoramic radiograph showed that the non-vascularized fibular flaps survived after 12 months (a). The titanium plate was removed (b)

osteomyocutaneous flap with severe vascular crisis to the non-vascularized fibular graft.

In this study, two vascularized fibular flaps with severe vascular crisis were timely managed with non-vascularized fibular grafts, and they had survived at the 25 and 69 months of follow-ups. More importantly, the facial contours of these patients were maintained even though there was partial absorption. Typically, such success should be attributed to the early detection of postoperative vascular crisis, favorable preoperative physical condition, small range of soft tissue defect, and no history of radiotherapy in these patients. Coincidentally, Xiao et al. [14] had recently reported 10 cases with vascular crisis, and non- vascularized fibular bone grafts were applied in these patients to compensate for the failure of free vascularized iliac bone flaps. The above findings show that the nonvascularized fibular graft is promising to serve as a remediation technique after failure of vascularized fibular flap, which contributes to the successful restoration segmental mandibular defects and facial contours of patients. In fact, some studies report that bone defects are reconstructed by the non-vascularized iliac bone grafts, and most of these bone defects are derived from limb bones such as the poor healing of scaphoid fracture [15], ankle joint [16], discontinuous femoral neck fracture [17], and defect due to giant cell tumor in distal radius [18]. On the other hand, Jeong

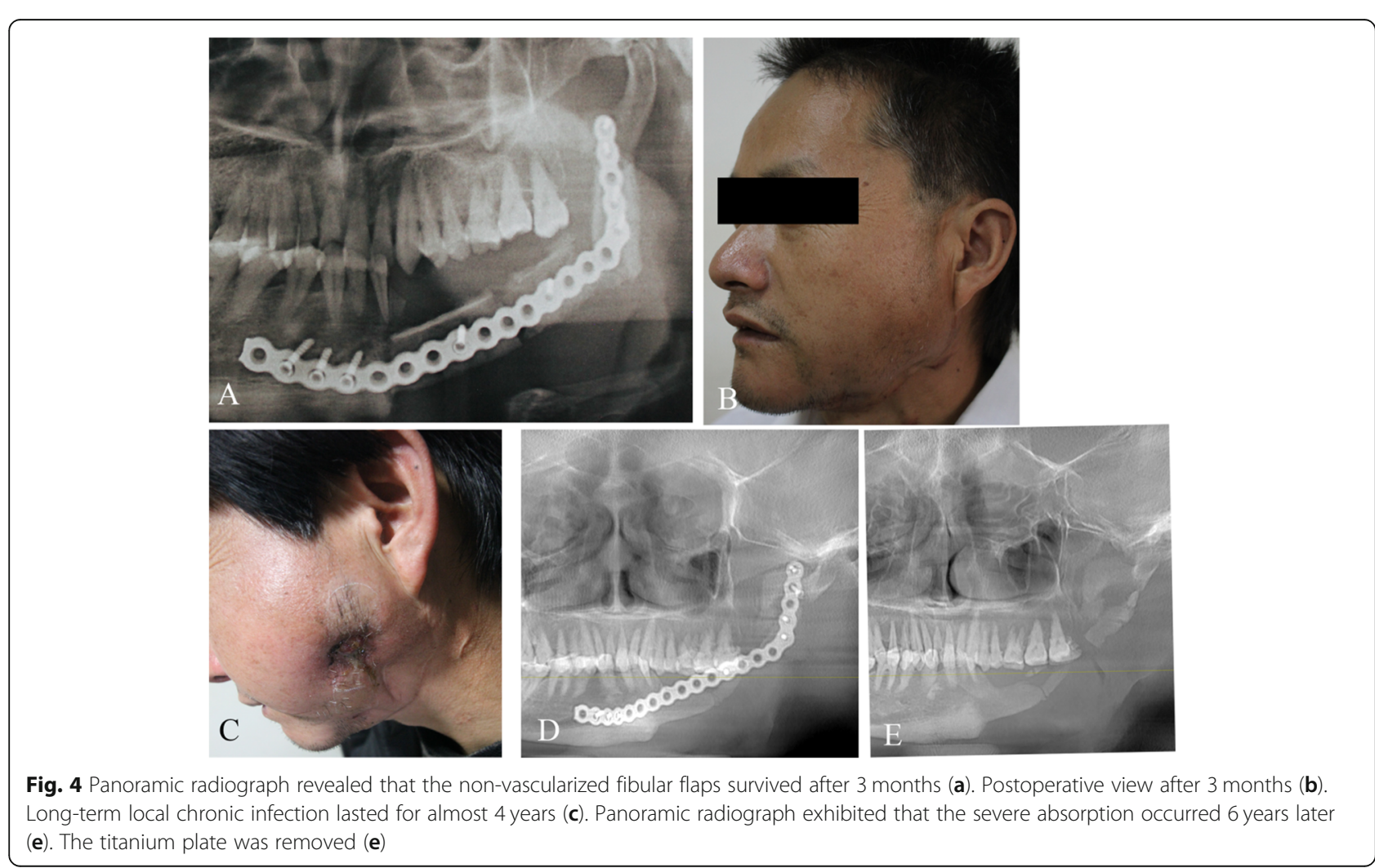


et al. [16] had successfully repaired one ankle joint with a 15-cm non-vascularized fibular flap. Moreover, Giordano et al. [19] also adopted a 21-cm non-vascular fibular flap to successfully repair the distal femoral condyle defect in an 86-year-old patient. All these successful cases mentioned above have indicated that it is feasible to reconstruct bone defects with the non-vascular fibula in clinical practice [20]. For instance, Lee et al. [21] and Wang et al. [22] had fixed the vascularized fibular flap to the mandibular base and placed the residual non-vascularized fibula onto the vascularized fibular flap to improve the height of the reconstructed mandible. These studies have partially suggested that, it is feasible to partially repair a mandibular defect with non-vascularized fibula, but it remains unclear about whether there is a significant difference between the planned non-vascularized fibula and the one changed based on a vascularized fibular flap due to severe vascular crisis. Nevertheless, in any case, the early detection of postoperative vascular crisis is the key to the success of this technique. Therefore, efforts should be made to guarantee a perforator flap in the vascularized fibular flap so as to facilitate postoperative observation. Among the 7 patients with vascular crisis in this study, two had no perforator flap (even during surgical exploration), but the fibular bone flap did not survive due to the lack of timely detection. However, in patients with L-shaped mandibular defects, the risk of venous crisis increases if the lower end of fibula is used to reconstruct the mandibular ramus where the perforator flap is located. Unfortunately, two patients in this study were encountered with venous crisis of the flap 2 days postoperatively, which was attributed to the above situation. Consequently, care should be taken to position the perforator flap and to avoid local compression in patients with L-shaped mandibular defects.

\section{Conclusions}

It is a relatively suitable temporary remediation technique to immediately change a vascularized fibular osteomyocutaneous flap with postoperative severe vascular crisis to a non-vascular fibula graft, which may avoid complete necrosis and the subsequent serious adverse consequences.

\section{Acknowledgements}

We thank Dr. Fanwei Qu for his amendment and revision of this manuscript.

\section{Authors' contributions}

Shengjie Shao, Weihong Wang, Biao Xu, Yu Liu, and Zhe Zhang participated in the clinical management of the patient, and Shengjie Shao wrote the manuscript. Weihong Wang was involved in the final editing. The author(s) read and approved the final manuscript.

\section{Funding}

This work was supported by the Yunnan health training project of high level talents (No. L-2018010) and the Science and Technology Innovation Team Project of Kunming Medical University (No. CXTD201711).

\section{Availability of data and materials}

All data utilized in this study are not public but are available from the corresponding authors upon reasonable request.

\section{Ethics approval and consent to participate}

All clinical procedures in this study were approval by the Human Body Science Committee of Kunming Medical University, and all patients signed informed consent before operation.

\section{Consent for publication}

All authors approved the final manuscript for publication.

\section{Competing interests}

The authors declare that they have no competing interests.

Received: 16 January 2020 Accepted: 19 February 2020

Published online: 29 February 2020

\section{References}

1. Hou JS, Chen M, Pan CB, Wang M, Wang JG, Zhang B, Tao Q, Wang C, Huang HZ. Application of CAD/CAM-assisted technique with surgical treatment in reconstruction of the mandible. J Craniomaxillofac Surg. 2012; 40:432-7.

2. Kumar BP, Venkatesh V, Kumar KA, Yadav BY, Mohan SR. Mandibular reconstruction: overview. J Maxillofac Oral Surg. 2016;15:425-41.

3. Ni Y, Lu P, Yang Z, Wang W, Dai W, Qi ZZ, Duan W, Xu ZF, Sun CF, Liu F. The application of fibular free flap with flexor hallucis longus in maxilla or mandible extensive defect: a comparison study with conventional flap. World J Surg Oncol. 2018;16:149.

4. Chen Y, Shen Z, Shao Z, Yu P, Wu J. Free flap monitoring using nearinfrared spectroscopy: a systemic review. Ann Plast Surg. 2016;76:590-7.

5. Deng R, Lu M, Yang X, Hu Q. A salvage operation for flap compromise following internal jugular venous thrombosis. J Craniofac Surg. 2011;22: 2426-7.

6. Guo QF, Xu ZH, Cai WS, Zhu JK. Monitoring island flap for fibular graft in 30 patients with long bone defects. Chin J Traumatol. 2003;6:275-9.

7. Largo RD, Selber JC, Garvey PB, Chang El, Hanasono MM, Yu P, Butler CE, Baumann DP. Outcome analysis of free flap salvage in outpatients presenting with microvascular compromise. Plast Reconstr Surg. 2018;141: 20-7

8. Nakamizo M, Yokoshima K, Yagi T. Use of free flaps for reconstruction in head and neck surgery: a retrospective study of 182 cases. Auris Nasus Larynx. 2004;31:269-73.

9. Yang Q, Ren ZH, Chickooree D, Wu HJ, Tan HY, Wang K, He ZJ, Gong CJ, Ram V, Zhang S. The effect of early detection of anterolateral thigh free flap crisis on the salvage success rate, based on 10 years of experience and 1072 flaps. Int J Oral Maxillofac Surg. 2014;43:1059-63.

10. Wang WH, Zhu J, Deng JY, Xia B, Xu B. Three-dimensional virtual technology in reconstruction of mandibular defect including condyle using double-barrel vascularized fibula flap. J Craniomaxillofac Surg. 2013;41:41722.

11. Wang $W H, X u B$. Maxillary reconstruction using vascularized fibular osteomyocutaneous flap and iliac bone through modified lateral lipsubmandibular approach. J Craniofac Surg. 2013;24:1453-7.

12. Brown JS, Lowe D, Kanatas A, Schache A. Mandibular reconstruction with vascularised bone flaps: a systematic review over 25 years. Br J Oral Maxillofac Surg. 2017;55:113-26.

13. Wijbenga JG, Schepers RH, Werker PM, Witjes MJ, Dijkstra PU. A systematic review of functional outcome and quality of life following reconstruction of maxillofacial defects using vascularized free fibula flaps and dental rehabilitation reveals poor data quality. J Plast Reconstr Aesthet Surg. 2016; 69:1024-36.

14. Xiao N, Zhang L, Peng X, Mao C, Zhang J, Cai ZG. Non-vascularised fibular bone graft after vascular crisis: compensation for the failure of vascularised fibular free flaps. Br J Oral Maxillofac Surg. 2018;56:667-70.

15. Uesato R, Toh S, Hayashi Y, Maniwa K, Ishibashi Y. Non-vascularized bone grafting in scaphoid nonunion: principles and type of fixation. Eur J Orthop Surg Traumatol. 2017;27:11-21.

16. Jeong ST, Park HB, Hwang SC, Kim DH, Nam DC. Use of intramedullary nonvascularized fibular graft with external fixation for revisional Charcot ankle fusion: a case report. J Foot Ankle Surg. 2012;51:249-53. 
17. Elgafy $H$, Ebraheim NA, Bach HG. Revision internal fixation and nonvascular fibular graft for femoral neck nonunion. J Trauma. 2011;70:169-73.

18. Agarwal S, Chawla S, Agarwal S, Agarwal P. Giant cell tumour 2nd metatarsal-result with en-bloc excision and autologous fibular grafting. Foot (Edinb). 2015;25:265-9

19. Giordano V, Parilha Coutinho B, Miyahira MK, de Souza FSM, do Amaral NP. Use of nonvascularized autologous fibular strut graft in the treatment of major bone defect after periprosthetic knee fracture. Case Rep Orthop. 2017;2017:1650194.

20. Estrella EP, Wang EH. A comparison of vascularized free fibular flaps and nonvascularized fibular grafts for reconstruction of long bone defects after tumor resection. J Reconstr Microsurg. 2017;33:194-205.

21. Lee JH, Kim MJ, Choi WS, Yoon PY, Ahn KM, Myung H, Hwang SJ, Seo BM, Choi JY, Choung PH, Kim SM. Concomitant reconstruction of mandibular basal and alveolar bone with a free fibular flap. Int J Oral Maxillofac Surg. 2004;33:150-6.

22. Wang W, Zhu J, Xu B, Xia B, Liu Y, Shao S. Reconstruction of mandibular defects using vascularized fibular osteomyocutaneous flap combined with nonvascularized fibular flap. Med Oral Patol Oral Cir Bucal. 2019;24:691-7.

\section{Publisher's Note}

Springer Nature remains neutral with regard to jurisdictional claims in published maps and institutional affiliations.

Ready to submit your research? Choose BMC and benefit from:

- fast, convenient online submission

- thorough peer review by experienced researchers in your field

- rapid publication on acceptance

- support for research data, including large and complex data types

- gold Open Access which fosters wider collaboration and increased citations

- maximum visibility for your research: over $100 \mathrm{M}$ website views per year

At BMC, research is always in progress.

Learn more biomedcentral.com/submissions 